\title{
Study of an effective structural system with rational parameters based on main energy principles
}

\author{
Katerina Toporkova ${ }^{1, *}$ \\ ${ }^{1}$ Building Designs Department, O.M. Beketov National University of Urban Economy, 91000, \\ Kharkiv, Ukraine
}

\begin{abstract}
The effective architectural and construction system with rational parameters based on main energy principles applied to construction of buildings and constructions with a small-step and largestep frames, representing the metal frame of full factory production collected in spatial system on high-strength bolts and previously strained combined prestressed concrete slabs which formed without timbering is proposed in this paper. The main constructive and technological features of the proposed frame, which allows reducing construction period, increasing working efficiency, and reducing labor intensity by using factory-made materials, quick erection of all process elements through the use of highstrength bolts is considered. The advantages of this constructive system in comparison with alternative systems are shown. The basic concepts of "rational decisions" to the design, namely, the objective of the optimal management of the structure parameters, which can not only improve its basic performance indicators, but also, and most importantly, improve operational reliability, is presented.
\end{abstract}

\section{Introduction}

In today's world, the construction of steel and reinforced concrete frames, both for singlestorey and multistorey buildings and structures, is very popular because of constructive and technological advantages of as compared to other systems.

The intensive growth of new design and technological developments opens up unlimited possibilities for the erection of objects implemented by one of the modern building methods, but each of these methods has a number of significant drawbacks.

Thus, for example, most of the shortcomings in the construction of a monolithic building are related to the characteristics of concrete which, depending on the building season or adverse weather conditions, require additional human and financial resources, which in turn has a significant impact on the cost and period of work execution [1]. The above shows one of the basic concepts of R. Descartes, represented by the thesis that any saving is ultimately a saving of time. In addition, the concrete casting process itself is

\footnotetext{
${ }^{*}$ Corresponding authors: tes290692@gmail.com
} 
highly labour-intensive and cost-based, and it requires expensive equipment for continuous supply of concrete mix, its consolidation and heating.

This was the reason for the creation of a new and effective form-factor that lies in the merging of the metal frame and the precast floor slabs with the use of high-strength bolts into a single system "S\&F" (the abbreviation - slabs and frame).

Objective of the study: Creation of a new structural system with rational parameters based on main energy principles.

Object of the study: Metal dimensional frame with prestressed concrete slabs which formed without timbering.

Subject of the study: Control parameters for this design.

\section{Construction and technological features of a design}

The proposed design found its application in two implementation alternatives, a large-step frame and a small-step frame (Fig. 1).
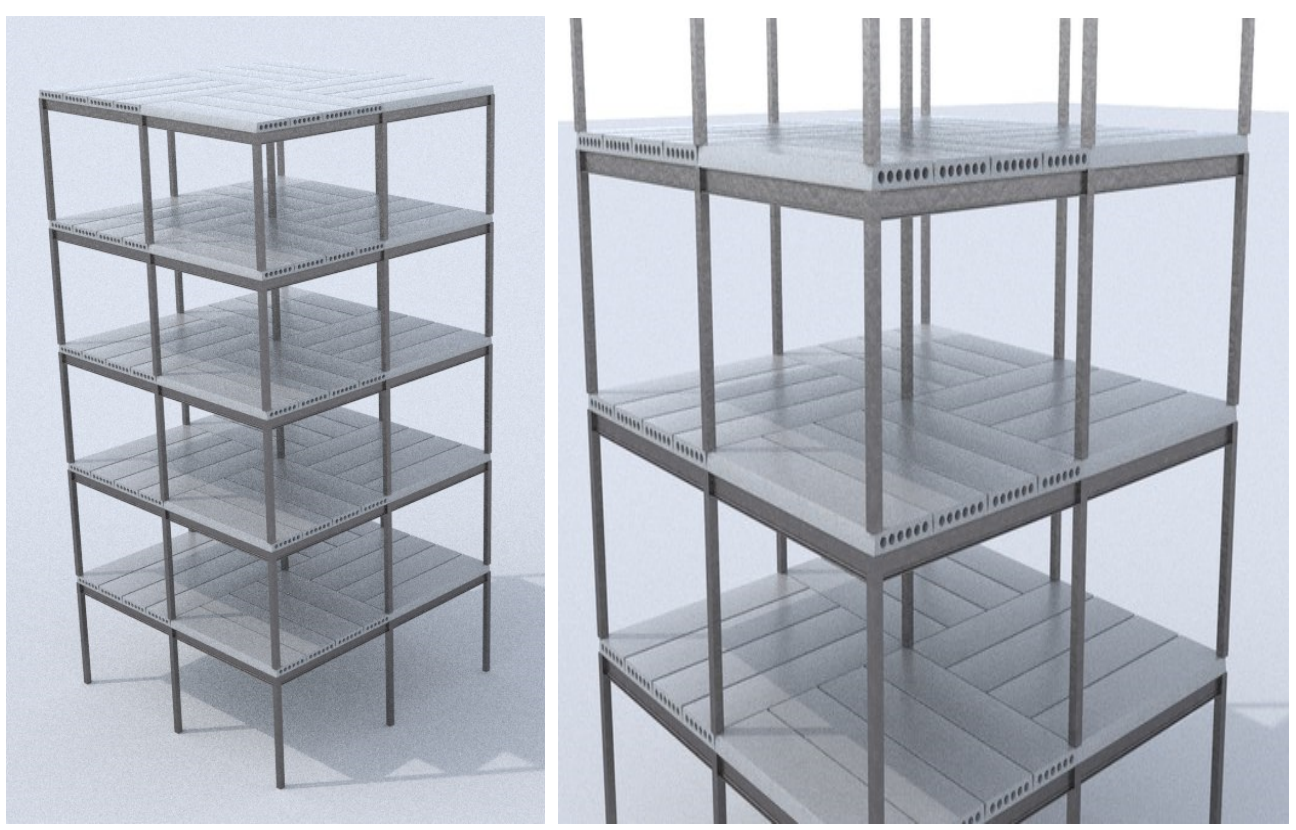

Fig. 1. Offered construction of a large-step frame.

In order to determine the qualitative indicators of the system, it is necessary to become familiar with the characteristics of its elements in particular and the integrity of the system as a whole, namely:

- Factory-made metal columns and girders, which are assembled into a dimensional system on high-strength bolts (usually from the rolled and, if necessary, perforated wasteless elements);

- Prestressed concrete slabs, which formed without timbering is considered [2];

- The small weight of the elements;

- Absence of protruding elements from the floor and ceiling planes;

- The possibility of using modern wall and roof cladding (any facade and roofing systems); 
- Rapid erection under the conditions of minimized labour-intensiveness of all technological operations (depending on the nomenclature of large and small mechanization);

- Almost unlimited combinatorics of architectural and planning concepts (owing to an arbitrary choice of steps and bays);

- Simple renovation of premises, if necessary;

- Year-round possibility of carrying out the construction works.

The most distinctive features are those of a large-step metal dimensional frame, with possible variation of cells $7,2 \times 7,2 \mathrm{~m} ; 9 \times 9 \mathrm{~m} ; 12 \times 12 \mathrm{~m}$.

The skeleton frame is formed by means of conjunction using highly-strength bolts of bridle wire columns and girders located in the same plane in two (not necessarily perpendicular) directions (Fig. 2).
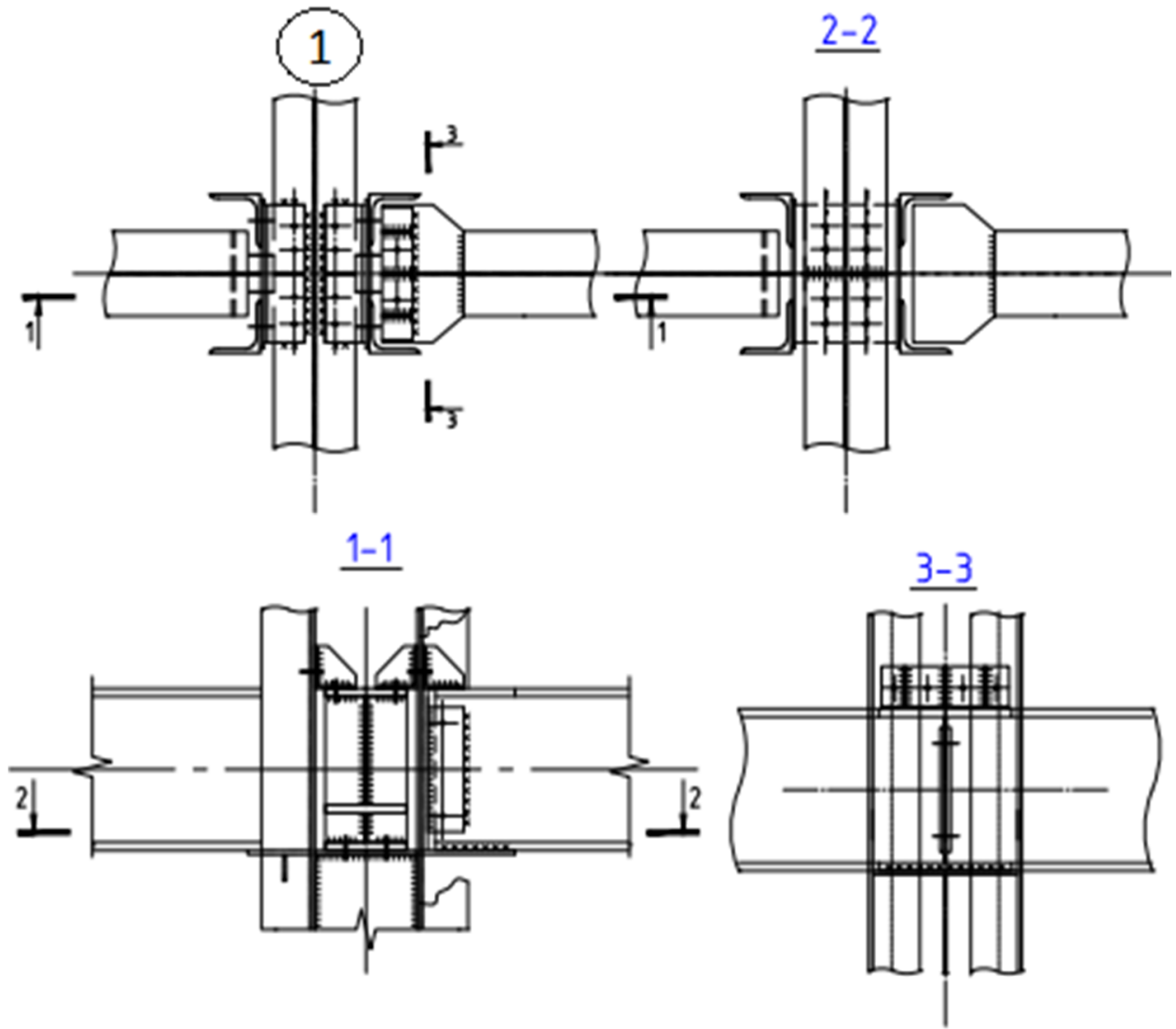

Fig. 2. The column and the girder junction on the high-strength bolts.

Moreover, girders and columns can be equipped with perforated walls, which are manufactured on a non-waste technology from a rolled section, resulting in the reduction of material consumption and structure cost [3]. An overlap is formed by means of combining prestressed concrete slabs which formed without timbering is considered with the rotation in adjacent cells by $90^{\circ}$, which in turn reduces the load on the girder two times (Fig.3). This property is reflected in the reduction of the size of the bolt section (the degree of perforation), that is, it forms the weight of the element. The proposed solution is fully consistent with the famous aphorism by B. Fuller: "If you want to measure the degree of a building perfection, weigh it." 


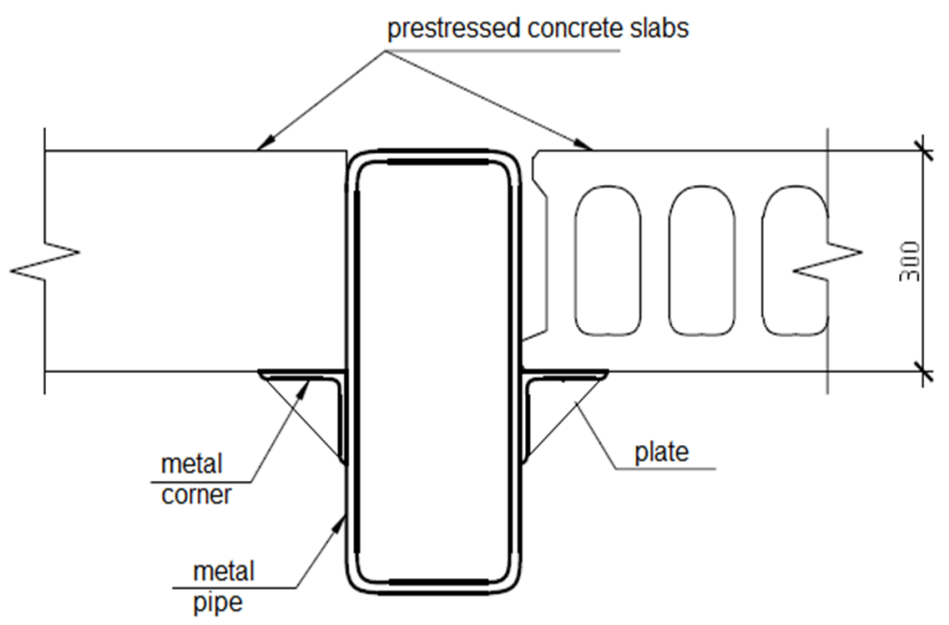

Fig.3. Slabs leaning on the girder.

In addition, the proposed slabs may have different lengths without loss of material. This decision is remarkable for the developed combination of space planning decisions, and an ability to create consoles in a designed building (Fig. 4).

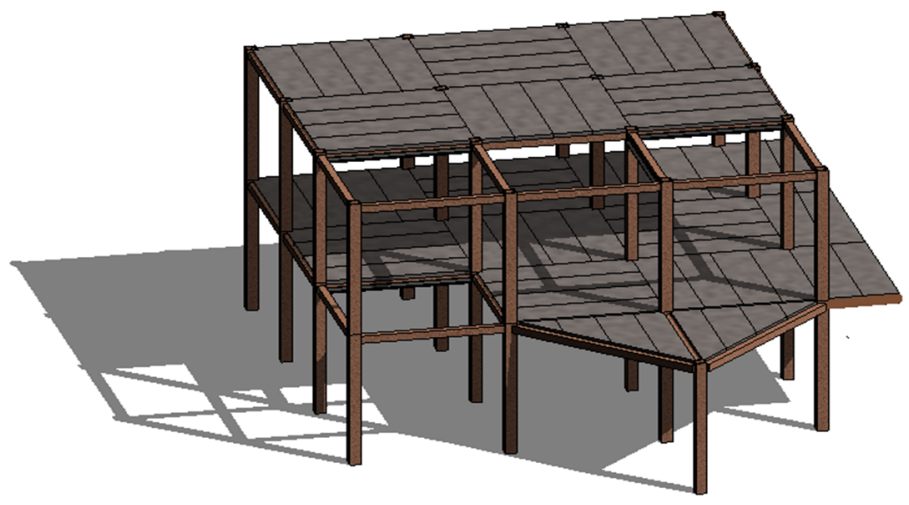

Fig. 4. Combinatorics of space planning decisions of metal frame.

Moreover, the use of heavy-duty concrete (C30/35 and above) avoids the use of the working transverse reinforcement and all types of structural reinforcement, which significantly reduces the price of the slabs.

In comparison with the monolithic reinforced concrete applied in recent years the pretension, system is less expensive and can be controlled at all stages of technological processes.

A construction arrangement of the frame can be braced and frame-braced. Number of storeys is calculated.

The stability and stiffness of the frame is ensured by the floor slabs and stiffening diaphragm (double girder, steel ties - portal or four-way the subsequent laying of foam concrete block or brick).

No less used for skeleton-type buildings is the small-step metal frame (the size of the cell does not exceed $6 \mathrm{~m}$ ). 
Small-step and large-step frames require creation of floor slabs operating as quasimonolithic system and consisting of pre-tensioned slabs and reinforcement frames with using fine-grained concrete on expanded cement. At that frames are fixed to crossbeams and create rigid floor slab where re-bars serve as connecting system to avoid sliding of slabs (Fig. 5).

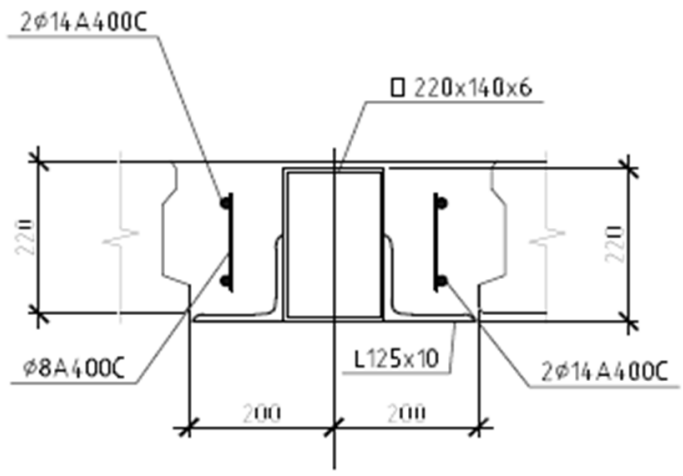

Fig. 5. Formation of a floor slab by means of reinforcement frames.

The main idea of the "S\&F" system is to create buildings with a small-step or large-step frame, depending on its purpose, which will allow the realization of a light transformation, including replanning and reshaping, organization of parking spaces, inbuilt or separate, commercial areas, if necessary (Fig. 6). At the same time, the use of high operational compatibility materials using bolted connection of elements reduces labour-intensiveness, resulting in the reduction of frame-construction time.
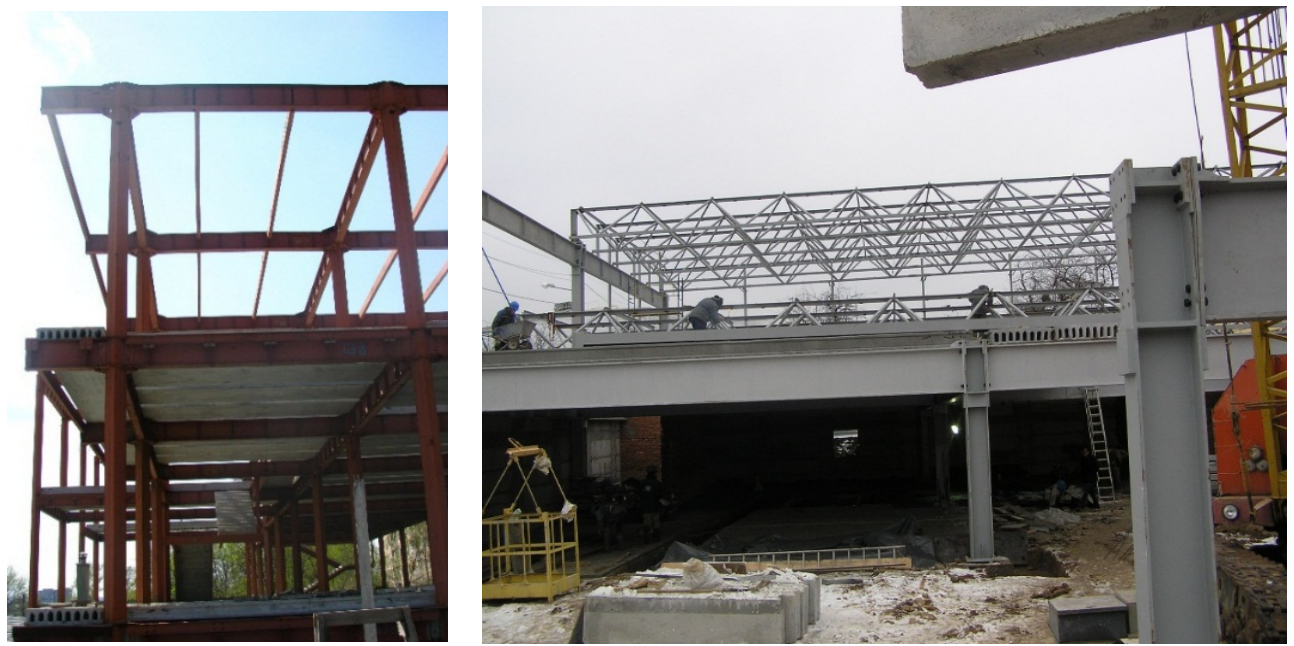

Fig. 6. Proposed frame under construction conditions.

\section{Rational decisions of construction}

An analysis of the available information has made it possible to define the basic concepts of "rational decisions" to the design, namely, the objectives of optimal management of structure parameters, which can not only significantly improve its basic performance indicators, but also, and most importantly, improve operational reliability. 
Management of the settings of rational systems consists of the creation of iterative procedures that gradually improve the geometric and/or physical-mechanical parameters of the design.

The frame system is characterized by some external and internal parameters. External parameters describe the resistibility of the system while the total volume of the material remains unchanged. For example, these parameters define the dimensions of the elements, the coordinates of the reference links, the coordinates of the external loads locations, their types and so on. The internal parameters describe the topology, volume and properties of the specified materials [4].

The provided ideology found its display in two directions [5]:

- the adoption of a single target function as a criterion;

- adoption of an isoperimetric criterion that determines the regulation of the stressed and strained state (SSS) of the system.

Under these conditions, it may be possible to achieve a significant simplification in defining the rationalization of the design parameters problem. It is also assumed that a uniform record of the target function could be replaced by the traditional criteria (cost, weight, volume, etc.) by one, and related to the nature and characteristics of SSS.

This requirement also applies to the restrictions governing the SSS management.

In turn, the virtual diversity of limitations that form the scope of permissible solutions (SPS) has led to the creation of a two-stage procedure:

- search for an ideal decision;

- formation of a final decision.

In order to create an ideal decision, new provisions are applied which are based on energy principles, namely:

- the provisions that for managed systems with a fixed amount of material, a number of external and internal links under a static external load - self-weight, the potential energy of deformation (PED) after conversion reaches the lower bottom on a rational combination of geometric values [5]:

$$
U=\inf _{a} U(a)^{k} \quad k=1,2 \ldots \infty,
$$

where $U$ - PED; $k$ - number of the comparison option; $a \in \mathrm{M} ; M$ - multitude of the allowed values of external geometric parameters.

The condition (1) can be distributed if there is a dominant among multiple virtual loads. For example, you can minimize the torque while creating a thin-walled element that has a bending strain with torsion by passing a load vector through the center of the bend, which in turn corresponds to the position (1) [5];

- the conditions of the isoenergetic state of the system (structure), i.e. when

$$
e[\{\bar{x}\}]=\text { const }
$$

where $e$ - is the density of the potential energy of deformation (DPED);

- $\{x\}$ - a vector of internal parameters.

Solving of practical task per condition (1) proves its operating efficiency, and also possibility to control geometric and physical \& mechanical properties of structural element.

In the process the above information analyzing the calculation of potential energy of deformation of the beam with perforated wall for the frame with a pitch of 9x9 $\mathrm{m}$ and load of $4,5 \mathrm{t} / \mathrm{m}$ in LIRA software complex was performed. Beam size was calculated based on condition that maximum rolled I-beam 60 does not fit as per two ultimate conditions [6]. At that the calculation of potential energy of deformation of the same beam with continuous wall was performed (Fig. 7). 


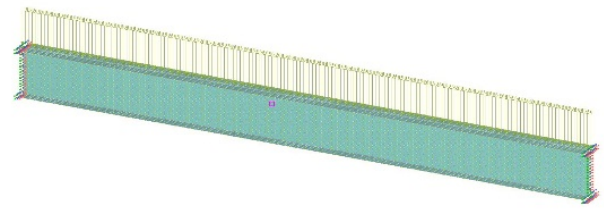

$\sum_{-x}$
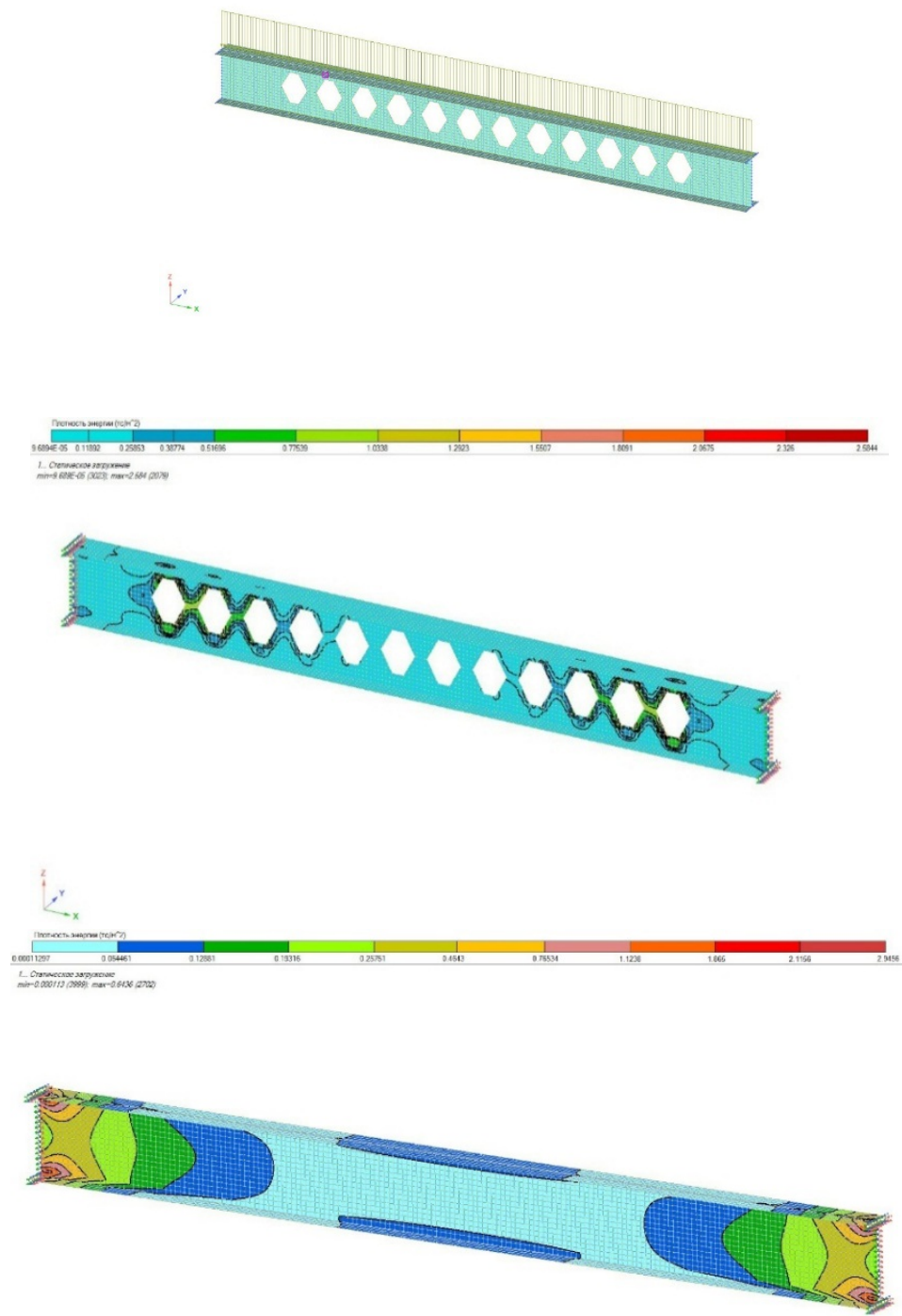

$\sum_{-x}^{2}$

Fig. 7. Potential energy of deformation of the beam with perforated wall. 
Calculation results have showed that PED for the beam with perforated wall is less than for the beam with continuous wall; moreover, the weight of perforated beam is much less than the weight of continuous beam resulting in cost-cutting of structure and system as a whole.

\section{Conclusion}

Application of steel and reinforced concrete frame with prestressed concrete hollow slabs which formed without timbering for construction of buildings and structures allows reducing construction period, increasing working efficiency, and reducing labor intensity by using factory-made materials, quick erection of all process elements, and also selection of optimum structural elements with rational parameters based on energy principles.

\section{References}

1. S.M. Anpilov, Tehnologiya vozvedeniya zdaniy $i$ sooruzheniy iz monolitnogo zhelezobetona. Uchebnoe posobie (Izdatelstvo Assotsiatsii stroitelnyih vuzov, Moscow, 2010)

2. V.S. Shmukler, E.G. Stoyanov, O.M. Pustovoytova, E.N. Tertyichnyiy, I.G. Lvovskiy, R.V. Korenev, Komunalne gospodarstvo mist, 114, 22-31 (2014)

3. B.S. Taranath, Structural analysis and design of tall buildings (CRC press, NW, 2016)

4. V.S. Shmukler, Yu.A. Klimov, N.P. Burak, Karkasnyie sistemyi oblegchennogo tipa (Zolotyie stranitsyi, Kharkiv, 2008)

5. V.S. Shmukler, Collective scientific works of UkrSURT, Kharkiv, 167, 54-69 (2017)

6. DSTU B V.1.2-3:2006. Progini ta peremishennya. Vimogi proektuvannya, Kiev (2006) 